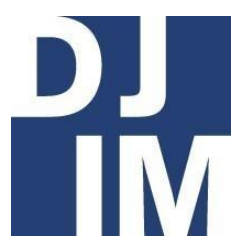

Volume 15

Spring

2019

djim.management.dal.ca |

\title{
Bitesize: Exploring the Form, Function, and Future of Online Book Summary Services
}

\author{
Conor Falvey
}

School of Information Management, Dalhousie University

\begin{abstract}
Popular book summaries are an under-researched family of information objects. Online book summary services offer condensed versions of popular press non-fiction books, especially titles related to management and leadership, for busy readers willing to pay subscription fees. These summaries are intended to be mobile, electronic, quickly-digested alternatives to reading entire books. Summaries can function as tools of learning as well as aids to book discovery. This paper describes the offerings of three online book summary services. It then discusses the implications of such services for information in society. It considers the benefits and drawbacks of the choice to focus these services on popular press nonfiction, which has commercial value and mainstream appeal, rather than other knowledge sources which might be more robust but less desirable to readers. Finally, it examines the ways in which artificial intelligence and natural language processing technologies could transform and disrupt the current system of producing and consuming book summaries.
\end{abstract}

Keywords: Book summaries, popular non-fiction, microlearning, text summarization, natural language processing 


\section{Introduction}

Book summaries are everywhere. Book reviews, still common in print newspapers and magazines even as they proliferate online, contain summaries. The blurbs on dust jackets and the description on a book's Amazon page contain summaries. If a book is non-fiction, it probably contains one or more summaries of its own contents - in the introduction, conclusion, or at the beginning or end of individual chapters. If it contains citations or any form of literature review, the references may constitute mini-summaries of other books. And of course, during regular conversation, our friends and colleagues provide summaries of books they have read, inviting us to react or discuss.

Since the popularization of the internet, the so-called "information explosion" has convinced more readers that they lack the time to read the number of books they should. Therefore, some have begun relying on book summaries. A plethora of online subscription services has arisen, selling brief, easy-to-read summaries of popular nonfiction titles. Services such as Blinkist, Joosr, and GetAbstract market themselves as tools for lifelong learning, particularly for busy professionals striving to remain "up to date" on popular knowledge trends that could influence their work life. Book summary services, particularly those that focus on business and management publications, are not a new phenomenon, but the rise of online modes of reading has given them new relevance (Leu et al., 2011).

Such services are slightly controversial. Literary purists have argued that reading summaries, rather than full books, is an assault on readership. Yet others see the value in summaries for "readers with more curiosity than time" (Coldewey, 2018, para. 8). In a Guardian review of one such service, Blinkist, a first-time user argued:

It's easy for literary journalists to forget that for many people, the choice isn't between reading Gillian Flynn and Gustave Flaubert, but between reading and not... We have to get over the idea that spending hours in a mahogany chair, frowning over a leatherbound volume from 1623 is the best way to absorb information. (Shipley, 2016, para. 6-8)

Even some advanced literary scholars, like Pierre Bayard, argue that there is no shame in being a "non-reader" who builds a secondary familiarity with books without actually reading the primary texts (Bayard, 2009). The books themselves, as information objects, are not as important as "the gossip that they generate; the ideas that they spawn; the conflicts that they provoke...Thus, it is only ever necessary to get a rough sense of what any particular book is about - and where to place it in the 'collective library'" (Lichtig, 2008, para. 5). Viewed through this lens, book summaries are unambiguously useful. If there is intellectual benefit in participating in popular discussion of new ideas, then 
being able to acquire rapid familiarity with influential or popular books has value.

This paper describes the offerings of three online book summary services. It then discusses the implications of such services for information in society. It considers the benefits and drawbacks of the choice to focus these services on popular press nonfiction, rather than other knowledge sources. Finally, it examines the ways in which artificial intelligence and natural language processing technologies could transform and disrupt the current system of producing and consuming book summaries.

\section{Description of Book Summary Services}

Services that sell summaries of popular books, re-formatted for quick and easy consumption, are not a recent innovation. The basis for the prevailing book summary format was established by Soundview Executive Summaries in 1978, when it began selling eight-page text and 20minute audio summaries of popular business books (Soundview, 2018). In the late 1980s, the publisher Macmillan ran a subsidiary that sold summaries of popular business books on audio-cassette ("Master a 300-page business book," 1987). For at least the past decade, EBSCO has offered access to a service called Business Book Summaries, which provides multi-level summaries of the most popular business books each year (Martin, 2009). EBSCO has recently partnered with Harvard Business Review to summarize its top publications as well (Peterson-Sloss, 2013). At present, numerous Internet and app-based summary services, including Soundview, are only a Google search away.

To get a better sense of what these services offer, I used and reviewed three subscription services that offer summaries of popular nonfiction: Blinkist, Joosr, and getAbstract. These services were among the top results returned by a Google search for "book summary service." Other services, including Soundview, were excluded from analysis because they did not offer a temporary free trial period before purchase. All services were analyzed on a laptop using a Chrome internet browser. Therefore, some comments regarding user interface and features may not generalize to mobile apps. As this analysis was quite rudimentary, it is not possible to comment on the extent to which the user experience may have been personalized to the researcher, and therefore may not be shared by other users. Blinkist

Blinkist (www.blinkist.com) was founded in 2012 in Berlin (Blinkist, 2018b; Coldewey, 2018). It now advertises a library of 2,500 summaries, growing at a rate of 40 titles per month, accessed by 6 to 7 million users. As of November 2018, those users purchase either an individual subscription from around $\$ 80$ to $\$ 150$ USD per year, or a team subscription for up to 10 users starting at $\$ 549$ USD. The Blinkist library is organized into 27 categories, covering a broad cross-section of popular nonfiction, including management and leadership, self-improvement, health and wellness, 
science and technology, and miscellaneous social science and humanities categories (such as history, economics, and religion).

A Blinkist book summary, referred to as a "blink," can be accessed in audio or textual format. The text version consists of roughly eight to 12 subsections, each on a separate page, containing around 250 words of summary text organized into short paragraphs of three to five lines. Each subsection begins and ends with repetition of one overall summary statement, highlighted in large bold text, representing a key message of the book. Users can navigate among the subsections using a table of contents in a collapsible sidebar. The blink culminates in a final summary page that compiles the key message headings into a single overview of the book. Blinks also include "highlights", which are bullet points of the book's main takeaways. A distinctive feature of Blinkist is that these highlights can be saved to your personal "Highlights" section, where you can sort, rearrange, and combine them with highlights from other books.

When searching for blinks, the user can view a preview page with an extremely brief book synopsis, an equally brief biography of the author, and Blinkist's recommendation as to which types of readers may be interested in the book. The preview page lists an estimated reading and/or listening time for the blink, usually between 10 and 20 minutes. Preview pages also include a link to buy the book, suggesting the app's utility as a book discovery tool for readers (and therefore a book sales tool for publishers). Some previews include a counter of how many times the summary has been read by Blinkist users. Read counts vary widely, with many titles drawing a few thousand reads and a smaller selection earning read counts in excess of 65,000 .

\section{Joosr}

Joosr (joosr.com) is a relatively new entrant to the book summary field, established circa 2014 in the United Kingdom by a figure identified on the company website only as "Darren, a businessman with a demanding job and a long daily commute" (Joosr, 2016). The service advertises a library of 250 summaries and a user base of 40,000 customers. Various subscription plans are available, ranging in price from $\$ 5.99$ to $\$ 7.99$ per month. Summaries are organized into 22 categories, somewhat dominated by business and selfimprovement topics, but include other nonfiction types such as history and science.

Each book summary contains 12 to 20 pages, presented as a text-only slideshow, with arrows at left and right for navigating backwards and forwards between slides. Each section opens with a bolded heading of the key message, followed by a few paragraphs of summary text adding up to around 300-400 words. The entire summary ends with a summary of four to six key takeaways, organized in bullet points. The summaries also contain a slide labelled "Now read the book," which contains a few paragraphs further promoting the book 
and the author. Unlike most other summary services, Joosr does not offer audio options or an estimate of reading time.

\section{GetAbstract}

GetAbstract (www.getabstract.com) was founded in 1999 in Lucerne, Switzerland, by Patrick Brigger and Thomas Bergen (GetAbstract, 2018a). It is a slightly more technical service than either Blinkist or Joosr, with a specific focus on business publications. In addition to book summaries, it provides summaries of articles, opinion pieces, and talks by business leaders. As such, it has a larger library than the other services, claiming to offer "tens of thousands" of unique summaries to "more than 1 million subscribers...including $20 \%$ of the Fortune 500 companies" (GetAbstract, 2018b). Individual subscriptions run $\$ 99$ to $\$ 149$ per year, while team plans are available for $\$ 999$ per year or more. Since all its summaries fit under the broad category of "business," GetAbstract organizes its titles by more granular subject headings - such as artificial intelligence, blockchain, and stress - into groupings it calls "channels".

Unlike the other services analyzed, GetAbstract presents its summaries on a single webpage, like a blog post, rather than displaying one section at a time like a slideshow. Summaries are divided into roughly eight to 12 subsections of about 100-200 words, demarcated by bold headings and interspersed with key quotations. Each summary opens with a "Recommendation" section suggesting why the book summary matters and who should read it, as well as a bullet point overview of the entire summary's key points. Summaries are also given a rating out of 10, alongside three sub-ratings for Innovation, Applicability, and Style. What these categories mean and how the ratings are calculated is opaque. Users can like or comment on summaries.

\section{Information Anxiety and Book Reading}

The existence, popularity, and overall marketing strategy of these book summary services speak to certain attitudes among their users. First, ongoing professional development (lifelong learning) is seen as a crucial route to long-term success, both for individuals and organizations. "In a world of constant change, it's learning that makes the winners," Blinkist tells prospective customers on its homepage (Blinkist, 2018b). This message bolsters the value proposition of a subscription to these services: if ongoing professional development can lead to job market success or increased business revenue, then it may be seen as a worthwhile financial investment in a way that learning-forpleasure is not. This valuation of practical business knowledge over other kinds of knowledge explains why book summary services first originated for business books and continue to favour this genre.

Second, book summary readers are faced with a glut of information to process and knowledge to acquire, but lack sufficient time to engage with it. According to Joosr's 
website, "the world is busy, demanding and fast-paced. It can seem impossible to find the time to keep up with reading and learning" (Joosr, 2016). Blinkist's sales pitch similarly laments that "almost none of us have the time to read everything we'd like to read" (Blinkist, 2018a). Book summary services claim to offer a solution by providing small units of learning, designed to fit into spare moments throughout the day alongside other commitments. Joosr and Blinkist's websites repeatedly describe their summaries as "bitesize," while Blinkist asks: "What if we could turn...little blocks of unallocated time into precious and rewarding moments for learning and reflection?" (Blinkist, 2018a). All services emphasize the low time commitment involved in consuming a summary advertised as roughly 15-20 minutes, with slight variations among different services. The consistent marketing message is that, by reading book summaries, busy people with little time for formal learning can continue to acquire knowledge (or at least familiarize themselves with new subjects) without altering their lifestyle or workload.

The discontent and stress associated with excessive information is sometimes referred to as "information overload" (as well as various synonyms like "information anxiety," "infobesity," etc.) (Bawden \& Robinson, 2009). Information overload is a time-honoured phenomenon given new relevance by the Internet age. As Bawden and Robinson write:
Innovations in information technology, such as the printed book, the periodical magazine or journal, the abstracting journal and the computer, have all led to complaints that it is impossible to keep up with the amount of information available. Such complaints have increased steadily over time. (Bawden \& Robinson, 2009, 183)

In this context, anxiety about remaining up to date in one's areas of interest and specialization is both a driver and a challenge for lifelong learning (Candy, 2002). Everyone wants to keep up, even though it is impossible. Book summary services capitalize on this information anxiety, for better or worse.

Whether book summary services help readers manage knowledge effectively is an open question, and one ripe for empirical research. It is possible that their greatest impact may be as tools of book discovery, rather than book replacement. Niklas Jansen, co-founder of Blinkist asserts that "Blinkist is not intended to replace the book...We think of Blinkist as the bridge between no book and the book. There's always a case why you should go on and buy the full book afterwards" (Coldewey, 2018, para. 6). Indeed, Blinkist and Joosr provide links to buy the original book alongside their summaries. So does EBSCO's Business Book Summaries service, which is explicitly intended as a book discovery tool (Martin, 2009). While Jansen's sentiments may be genuine, his approach is likely the only viable one for a book summary service given copyright 
restrictions in most countries. Publishers must grant these services the right to substantially reproduce and resell their books. The fact that they have done so indicates that publishers do not view book summary services as serious competition, and indeed may see them as another form of promotion for their book. This suggests that readers use book summaries in much the same way as book reviews or article abstracts - as a means to make a quick judgement on whether they want to read the entire document.

\section{Merits and Perils of Popular Press Nonfiction}

Popular nonfiction books, intended for a general audience, are an important venue for the creation, dissemination, and legitimation of knowledge. The realm of business management, where many book summary services focus their efforts, provides an excellent case study. While there is prolific academic study of management theories and practices, popular nonfiction serves an important role in translating academic concepts and research findings into public knowledge (Mazza \& Alvarez, 2000). Managers report that reading popular books about their field makes them feel more confident and well-informed (Lewis, Schmisseur, Stephens, \& Weir, 2006). Previous analyses have found that much popular management writing presents advice that is fundamentally sound, and often in line with prevailing academic thinking (Lewis et al., 2006).
The chief advantage of popular nonfiction over primary academic sources is its accessibility to general audiences. Typical popular nonfiction prose is non-technical and conversational, aimed at moderately educated readers without specialized backgrounds in the topic at hand. At their best, popular books can transform dry or esoteric subjects in domains like economics, chemistry, psychology, or history into pleasurable reading material that seems relevant to everyday life. Because of this, some educators have explored the use of popular non-fiction as a teaching tool in post-secondary classrooms (Amaral \& Shibley, 2010; Benedict, 2013; Mills, 2014). Results have frequently been promising, with students often viewing these texts as non-intimidating pathways into challenging subject matter.

However, popular press nonfiction has its flaws. First, its content may be too simplified. Advice in popular nonfiction books is often presented in a strippeddown, generalized manner at the expense of useful context or explanations of underlying theory (Lewis et al., 2006). This is not necessarily a failing - sometimes a simplified snapshot of a subject is all that the reader requires. However, it can be problematic if readers believe they are receiving a fuller explanation of the topic than is actually the case. Second, popular press nonfiction books may have been edited or fact-checked but do not undergo peer-review to establish that their contents are valid, accurate, and worthy of 
consideration. Topics may have been chosen not for their value as knowledge, but for their novelty or sensationalism, the author's celebrity status, or other factors influencing the book's marketability. Third, reliance on popular press sources can promote faddishness, trend-following, and unhelpful turnover of ideas. In the business world, the popularity of "guru-advice books" has been accused of causing excessive change within organizations as decisionmakers attempt to uncritically implement each passing fad in management thinking (Lewis et al., 2006). By increasing access to such advice, book summary services could exacerbate this problem.

Regardless of their positive or negative effects, popular books play a significant role in the spread of knowledge in society and will likely continue to do so. As a general category, adult nonfiction outsells adult fiction in the United States retail book market, with nonfiction sales increasing as fiction sales have declined in recent years (Milliot, 2018). According to retail sales data from NPD Bookscan, the bestselling nonfiction genres (apart from reference works and religious texts) are now "General Nonfiction,"

"Biography/Autobiography/Memoir," "Health/Fitness/Medicine/Sports,"

"History/Law/Political Science" and "Business/Economics" (Milliot, 2018). Unsurprisingly, these genres are wellrepresented in general interest book summary services such as Joosr and Blinkist.
The existing demand for popular nonfiction titles is an asset to book summary services. This fact, more than any judgements as to the quality of knowledge contained in popular non-fiction books, is probably why these services focus primarily on popular, bestselling titles by well-known authors. Not only do these titles come pre-vetted and approved by a professional editorial team and the buying public, but they have usually been supported by extensive publicity efforts by their original publishers. Their popularity then becomes a selling point for book summary services. Thus, the summarizers advertise works by "leading thinkers" (Blinkist, 2018b) and "the world's most renowned thought leaders" (GetAbstract, 2018a), assuring customers that the titles chosen for summary are "the most influential and important" (GetAbstract, 2018b) and "the most relevant" (Joosr, 2016).

From a business perspective, it is difficult to fault book summary services for capitalizing on the immense popularity of non-fiction titles like Sheryl Sandberg's Lean In or Margot Lee Shetterly's Hidden Figures (both of which are available as Blinkist summaries). Nor is it helpful or appropriate to criticize readers for preferring to consume popular press nonfiction books in the first place. However, the exclusive choice of popular press nonfiction as the basis of these services limits their utility as knowledge management tools or meaningful sources of lifelong learning. A service that also sold engaging, 
plain-language summaries of scholarly works or research reports would be perhaps be more useful for serious learners.

\section{Automated Text Summarization}

Currently, the book summary services profiled above sell a product that is largely human-created, rather than machinegenerated. Blinkist in particular has made this a marketing platform, adopting the motto "Humans before algorithms" (Blinkist, 2018a). One popular press review of Blinkist approved: "Anyone can read a book and give you a rundown of each chapter, and there are automated summary services that will do something like that, as well. But it takes someone familiar with the field and well-versed in how to communicate that information to do it well." (Shipley, 2016). In Blinkist's case, book summaries are produced with input from a network of freelance experts (Coldewey, 2018), although interestingly the blinks do not credit their human summarizers by name. No public data could be found on the behind-the-scenes methodologies of either Joosr or GetAbstract. In any case, none of the three services has publicly identified a role for artificial intelligence in generating summaries.

Text analysis and summarization has long been a topic of inquiry in the field of machine learning. Software that conducts text mining, or other analyses of qualitative data, is now widely available. The majority of this software is designed for the needs of corporate customers, who might use it to process thousands or millions of social media posts about their products (Harris, n.d.). Basic text analysis software can perform functions like counting keywords or phrases, detecting duplicate information, recognizing named entities (like people or places), or measuring whether a text expresses positive or negative sentiment (Harris, n.d.). Emerging technology will enable AI to detect whether sentences are paraphrases of each other (Cordeiro, Dias, \& Brazdil, 2007; Kravchenko, 2018). Meanwhile, some familiar everyday applications of natural language processing include automated multilingual translation services like Google Translate (Korbut, 2017) and Facebook's defunct "trending topics" feature, which dynamically summarized chatter about news stories on the social network until earlier this year ("Under the hood," 2014).

Producing a Blinkist-like summary of a complex text is a challenge for artificial intelligence at this stage, but it is rapidly becoming more feasible (Avinesh, Hättasch, Özyurt, Binnig, \& Meyer, 2018; Goularte, Nassar, Fileto, \& Saggion, 2019; Lynn, Choi, \& Kim, 2018). Already, applications are available online that purport to generate summaries of text. These applications, like Resoomer

(resoomer.com), TextSummarization (textsummarization.net) or the Open Text Summarizer (splitbrain.org), are still quite rough. Based on personal use, results vary in quality. This is partly because the applications are primarily designed to condense - they identify statements that are likely to be 
significant to the document's overall meaning and delete what remains. This is only part of what humans does when they summarize a document. Paraphrasing, restructuring, or re-writing content are also important components of the human process.

Text condensers will make the leap to full summarizers when they incorporate automatic text generating capabilities. The technology already exists to empower computers to generate human-sounding text. It is currently being deployed, to great controversy, in the field of journalism. The Associated Press and other media outlets now use computer algorithms to autogenerate news stories on certain amenable topics (Graefe, 2016). As the technology develops, it will become increasingly able to personalize written news stories to an individual reader's interests and preferences. News-writing algorithms may even be able to answer a reader's questions by searching for relevant data and autogenerating a personalized textual summary of its findings (Graefe, 2016).

Given these developments, how much longer will book summary services and their customers continue to favour humangenerated summaries? Like many jobs, that of summarizer may soon become substantially automated. Clearly, newsroom journalists have reason to fear a similar fate. Employees of Joosr, Blinkist, and GetAbstract should brace themselves for automation.
In the long term, advanced text summarization software seems likely to put book summary services out of business. Information seekers will not need to purchase pre-made summaries if they have access to software that generates them on demand, to their personal specifications. But in the short term, book summary services could benefit greatly from incorporating natural language processing into their business model. Access to highly capable, user-friendly text summarizing software for personal use is still far in the future. Until it arrives, book summary services could (and probably will) use existing technology to speed up the summarizing process, over a wider variety of summaries, and lower costs by reducing personnel. They could enjoy a profitable heyday before being displaced by more elaborate artificial intelligence.

\section{Conclusion}

It is surprising that book summary services like Blinkist, Joosr, and GetAbstract have not been more closely studied as collections of information objects. Future empirical research could examine how readers use these services, whether the summaries promote learning, and whether organizations benefit from implementing book summary services as part of professional development programs. Usability studies of book summaries could be beneficial in the development of better e-learning tools. At a more theoretical level, comparative studies of book summaries and the original texts could provide insight 
into how readers determine a book's most significant messages, and which information is deemed extraneous.

Furthermore, a thorough understanding of how book summaries are created and read by humans could provide a conceptual model for the artificially intelligent summarizers of the future. In order to create useful and usable formats and delivery methods for computer-generated summaries using conventional technology, programmers will need strong humangenerated examples to create training sets. Summaries from Blinkist, Joosr, or GetAbstract could provide "gold standard" data for supervised machine learning, providing a benchmark towards which automated summarizers should strive.

Much of this paper has discussed the relationship between book summary services and popular press readership. However, these services have relevance to academic researchers as well. For one thing, there is an information explosion within academia, which complicates both knowledge production and the communication of scholarly knowledge to the public. Demand for popular book summary services should be seen as an argument in favour of improved abstracting, both of journal articles and academic books.

However, it should also be taken as a warning: academic texts may be more easily replaced by summaries in the minds of most readers, because unlike popular press books, much academic writing is Bitesize unpleasant to read (Pinker, 2014; Sweet, 2017). The visceral reading experience is not the draw - readers of academic writing want to extract information, assess it, and apply it. So imagine a service similar to Blinkist's "Highlights" function that would allow students, researchers, and lay-people to extract the bulleted research highlights provided with many publicly available abstracts of thousands of papers - or from the full text - to be stored in a personal library for endless unique combination and remixing (Wang, See-To, Lin, \& Li, 2018). Or imagine an automated summarizing service, such as those being pioneered in journalism, that would trawl academic databases for facts and claims, and compose a simple, readable summary about them, never requiring the reader to encounter a book or journal article at all. When there is no longer any great need for readers to interact with dense, impenetrable academic texts, what will happen to scholarly communications?

With so much at stake, the theory and practice of text summarization deserves to become a vibrant research concern outside of the computer science realm. Input will be required from information studies, social sciences, and the humanities in order to ensure that summarization technology develops with an understanding of the human and social dimensions of knowledge. Analysis of human-created book summary services is a promising place to start. 


\section{References}

Amaral, K. E., \& Shibley, I. A. (2010). Using popular nonfiction in organic chemistry: Teaching more than content. Journal of Chemical Education, 87(4), 400-404. https://doi.org/10.1021/ed800121 $\mathrm{n}$

Avinesh, P. V. S., Hättasch, B., Özyurt, O., Binnig, C., \& Meyer, C. M. (2018). Sherlock: A system for interactive summarization of large text collections. Proceedings of the VLDB Endowment, 11(12), 19021905.

https://doi.org/10.14778/3229863. 3236220

Bawden, D., \& Robinson, L. (2009). The dark side of information: Overload, anxiety and other paradoxes and pathologies. Journal of Information Science, 35(2), 180-191. https://doi.org/10.1177/01655515 08095781

Bayard, P. (2009). How to talk about books you haven't read. New York: Bloomsbury.

Benedict, J. (2013). Using popular-press nutrition books to develop critical reading skills of first-year college students. Journal of Nutrition Education and Behavior, 45(2), 188-190. https://doi.org/10.1016/j.jneb.2012 .07 .006
Blinkist. (2018a). About Blinkist. Retrieved November 29, 2018, from https://www.blinkist.com/en/about I

Blinkist. (2018b). Retrieved November 29, 2018, from https://www.blinkist.com/en/

Candy, P. (2002). Lifelong learning and information literacy (White paper). UNESCO, U.S. National Commission on Libraries and Information Science, \& National Forum on Information Literacy. Retrieved from https://www.researchgate.net/publ ication/268299706_Lifelong_Learni ng_and_Information_Literacy

Coldewey, D. (2018). As tech automates, Blinkist keeps its book summary service very human. Retrieved from https://techcrunch.com/2018/02/1 5/as-tech-automates-blinkistkeeps-its-book-summary-servicevery-human/

Cordeiro, J., Dias, G., \& Brazdil, P. (2007). A metric for paraphrase detection. In 2007 International MultiConference on Computing in the Global Information Technology (ICCGI'07) (pp. 7-7). Guadeloupe, French Caribbean: IEEE. https://doi.org/10.1109/ICCGI.2007 .4

GetAbstract. (2018a). About us. Retrieved December 7, 2018, from 
https://www.getabstract.com/en/a bout-us

GetAbstract. (2018b). Discover getAbstract's corporate solutions. Retrieved November 29, 2018, from https://www.getabstract.com/en/e nterprise/overview

Goularte, F. B., Nassar, S. M., Fileto, R., \& Saggion, H. (2019). A text summarization method based on fuzzy rules and applicable to automated assessment. Expert Systems with Applications, 115, 264-275. https://doi.org/10.1016/j.eswa.201 8.07.047

Graefe, A. (2016, January 7). Guide to automated journalism. Tow Center for Digital Journalism. Retrieved from https://www.cjr.org/tow_center_re ports/guide_to_automated_journal ism.php/

Harris, D. (n.d.). What is text analytics? We analyze the jargon. Software Advice. Retrieved from https://www.softwareadvice.com/r esources/what-is-text-analytics/

Joosr. (2016, October 24). About us. Retrieved November 29, 2018, from https://joosr.com/about

Korbut, D. (2017, August 1). Machine learning translation and the Google Translate algorithm.
Retrieved from https://blog.statsbot.co/machinelearning-translation-96f0ed8f19e4

Kravchenko, D. (2018). Paraphrase detection using machine translation and textual similarity algorithms (Master's thesis). BenGurion University of the Negev, Israel.

Leu, D., McVerry, J. G., O'Byrne, W. I., Kiili, C., Zawilinski, L., EverettCacopardo, H., ... Forzani, E. (2011). The new literacies of online reading comprehension: Expanding the literacy of learning curriculum. Journal of Adolescent \& Adult Literacy, 55(1), 5-14. https://doi.org/10.1598/JAAL.55.1. 1

Lewis, L. K., Schmisseur, A., Stephens, K., \& Weir, K. (2006). Advice on communicating during organizational change: The content of popular press books. Journal of Business Communication, 43(2), 113-137. https://doi.org/10.1177/00219436 05285355

Lichtig, T. (2008, January 6). Never read Ulysses? Me neither. Retrieved from http://www.theguardian.com/book s/2008/jan/06/fiction.society

Lynn, H. M., Choi, C., \& Kim, P. (2018). An improved method of automatic text summarization for web 
contents using lexical chain with semantic-related terms. Soft Computing, 22(12), 4013-4023. https://doi.org/10.1007/s00500017-2612-9

Martin, J. A. (2009). Business book summaries. Choice, 46(8), 1474.

Master a 300-page business book in 45 minutes! (1987). Changing Times, 41(2), 77.

Mazza, C., \& Alvarez, J. L. (2000). Haute couture and prêt-à-porter: The popular press and the diffusion of management practices. Organization Studies, 21(3), 567588.

Milliot, J. (2018, January 19). Nonfiction categories continued to grow in 2017. Retrieved from https://www.publishersweekly.com /pw/by-topic/industrynews/bookselling/article/75877nonfiction-categories-continuedto-grow-in-2017.html

Mills, C. P. (2014). Trade book collections to support teaching economics undergraduates: Notes, suggestions, and bibliography. Journal of Business \& Finance Librarianship, 19(3), 256-274. https://doi.org/10.1080/08963568. 2014.916558

Peterson-Sloss, C. (2013, November). HBR press and EBSCO sign agreement. Information Today, 26.
Pinker, S. (2014, September 26). Why academics stink at writing. The Chronicle of Higher Education. Retrieved from https://www.chronicle.com/article/ Why-Academics-WritingStinks/148989

Shipley, D. (2016, June 23). Condensed, or just dense? The apps that turn books into 15-minute reads. The Guardian. Retrieved from https://www.theguardian.com/boo ks/booksblog/2016/jun/23/conden sed-apps-that-turn-books-into15-minute-reads-joosr-blinkist

Soundview Executive Book Summaries. (2018). About us. Retrieved December 7, 2018, from http://www.summary.com/about/

Sweet, S. (2017, August 21). Why academics revel in bad writing. The Walrus. Retrieved from https://thewalrus.ca/whyacademics-revel-in-bad-writing/

Under the hood: How Facebook built trending topics with natural language processing. (2014, January 16). Retrieved from https://venturebeat.com/2014/01/ 16/under-the-hood-howfacebook-built-trending-topicswith-natural-language-processing/

Wang, W. M., See-To, E. W. K., Lin, H. T., \& $\mathrm{Li}$, Z. (2018). Comparison of automatic extraction of research highlights and abstracts of journal 
articles. In Proceedings of the 2 nd International Conference on

Computer Science and Application Engineering - CSAE '18 (pp. 1-5).

Hohhot, China: ACM Press.

https://doi.org/10.1145/3207677.3

277979 